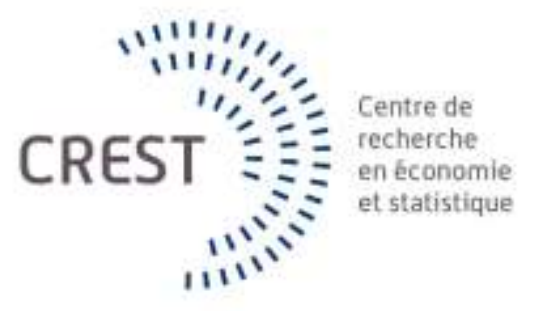

Série des Documents de Travail



Les documents de travail ne reflètent pas la position du CREST et n'engagent que leurs auteurs. Working papers do not reflect the position of CREST but only the views of the authors.

\footnotetext{
${ }^{1}$ Georgetown University

${ }^{2}$ London School of Economics

${ }^{3}$ CREST, Ecole Polytechnique. E-mail : alessandro.riboni@polytechnique.edu
} 


\title{
Legal Efficiency and Consistency*
}

\author{
LUCA ANDERLINI \\ LEONARDO FELLI \\ (Georgetown University) \\ (London School of Economics) \\ Alessandro Riboni \\ (CREST, Ecole Polytechnique)
}

May 2016

\begin{abstract}
We consider a stylized model of judicial decision making under common and civil law to study whether and why legal institutions affect economic outcomes. Judges are of two types: some judges are conservative and mechanically follow the precedent or the statute, while others maximize social welfare. The civil law and common law traditions have different centers of authority (legislatures vs. judges), but they also differ with respect to the timing of legal decisions (ex-ante vs. ex-post).

As a motivating example, we study the enforcement of property rights in courts. We analyze the efficiency and consistency of courts' decisions in both legal systems. We find that legal certainty is higher under common law than under civil law. We show that common law achieves higher expected welfare than civil law regime when the proportion of conservative judges is neither too low nor too high, and judges are sufficiently forward looking. In changing economic environments, civil law courts do not respond to economic shocks. Conversely, common law courts change the law only if shocks are persistent. Shock persistence is what makes common law more likely to dominate civil law because of its greater adaptability.
\end{abstract}

JEL Classification: D23, D86, C79, K12, K13.

KeYwords: Property Right Protection, Legal Origin, Time-Inconsistency, Investment, Legal Adaptability.

Address for CORRespondence: Alessandro Riboni, Department of Economics, Ecole Polytechnique, alessandro.riboni@polytechnique.edu

*This paper supersedes and substantially extends two previous papers by the same authors: "Statute Law or Case Law?" and "Courts' Decision Making without Commitment". We greatly benefited from comments by Henry Hansmann and seminar participants at Paris-Dauphine. Luca Anderlini and Alessandro Riboni thank EIEF (Rome) and LUISS University for their generous hospitality. 


\section{Introduction}

The consequences of legal institutions on the economy have been emphasized by many empirical studies. For instance, La Porta et al. $(1997,1998,1999)$ show that the common law tradition is associated with better protection of outside investors, more developed financial markets, and more secure property rights. ${ }^{1}$ Moreover, Djankov et al. (2003) find that common law courts are more consistent in that they treat similar people similarly. Rajan and Zingales (2003) and Lamoreaux and Rosenthal (2005) take a historical perspective and argue that common law countries had more developed financial markets than civil law countries only after World War II.

Since legal institutions put constraints on agents' behavior and affect the structure of incentives, it is not surprising that legal institutions have an effect on the economy. But, why does the legal origin (that is, the adoption of either common or civil law) affect economic outcomes? As pointed out by La Porta et al. (2004), “... despite [the above-mentioned] evidence, the exact mechanism through which legal origin matters has remained uncertain." To investigate this issue, this paper models in a stylized way judicial decision making under common and civil law. As a motivating example, we focus on the enforcement of property rights in courts.

We abandon the assumption that all courts mechanically enforce the statutes, the precedents, or the contractual terms. Instead, we assume that a fraction of courts are active, that is, they have some discretion in rule making. Economic agents when making investment decision do take into account future enforcement of property rights. It is through this mechanism that court's decisions influence economic outcomes. We solve for the rational expectations equilibrium of this model and compute the expected welfare under the common and civil law systems. We are thus able to compute the efficiency of both legal regimes and investigate the conditions under which one regime is preferable to the other. We also identify an additional objective of the legal system, besides efficiency, the uniformity and predictability of the law. We ask whether legal consistency is achieved under both legal systems and whether there is a trade-off between certainty in the law on the one hand and equitable decisions and flexibility on the other.

\footnotetext{
${ }^{1}$ See also Beck et al. (2003b). Spamann (2010), however, does not find an effect of common law on shareholder protection. Djankov et al., (2002) and Botero et al. (2004) analyze the effect of legal origins on regulation of new entry and labor markets. The legal origin literature is summarized by La Porta et al. (2008) and Nunn (2009).
} 
According to traditional comparative law doctrine, common law is mostly a judge-made law: the law is established by judicial precedents and decisions. ${ }^{2}$ Stare decisis is what requires courts under common law to conform to decisions reached by previous courts. ${ }^{3}$ Conversely, under civil law the center of authority is the legislature, and the role of civil law judges is to interpret and apply a body of statutes and administrative regulations. ${ }^{4}$

We assume that judges can be of two types. A fraction of judges mechanically follow the precedent (under common law) or the statute (under civil law). These judges, denoted as "conservative", believe that the law consists of a body of rules and that courts cannot act outside these rules. The remaining judges are "benevolent" (or active) and maximize social welfare. To some extent, this distinction captures the two main legal theories in American jurisprudence. On the one hand, proponents of legal formalism argue that judicial discretion poses a threat to legal certainty and to democratic legitimacy. ${ }^{5}$ On the other hand, the followers of instrumentalism believe that judges retain a considerable amount of discretion to fill in the gap of existing laws and that the law should be used as a tool to balance competing societal interests. ${ }^{6}$ In each period, the law is enforced by one of the two types of judges (either conservative or benevolent).

Civil law and common law have different centers of authority (legislatures vs. judges), but they also differ with respect to the timing of legal decisions (ex-ante vs. ex-post). On this point, Cooley (1868) writes: "[I]t is said that which distinguishes a judicial from a legislative act is that the one is a determination of what the existing law is in relation to some existing thing already done or happened, while the other is a predetermination of what the law shall be for the regulation of all future cases." 7

\footnotetext{
${ }^{2}$ See Calabresi (1982, ch. 9) for a discussion of the democratic legitimacy of court-made law.

${ }^{3}$ Stare decisis is a Latin term which literally means "to stand by things decided." The meaning of this rule is well captured by Radin (1933): "If a court follows a previous decision, because a revered master has uttered it, because it is the right decision, because it is logical, because it is just, [...] that is not an application of stare decisis. To make the act such an application, the previous decision must be followed because it is a previous decision and for no other reason."

${ }^{4}$ Civil law refuses any binding effect to previous judicial interpretation. Von Mehren (1957, ch. 16) argues that this principle holds in France, where even precedents by a hierarchically superior court are never binding, and to a lesser degree in Germany.

5 "The main danger in judicial interpretation $[\ldots]$ is that judges will mistake their own predilections for the law." Scalia (1989).

${ }^{6}$ For a comparison of instrumentalistic and formalistic legal theories, and their respective influence on American jurisprudence, see Summers (1982).

${ }^{7}$ There are, of course, other differences between the two legal traditions which are not modeled in this paper. For instance, the two systems differ in the ways of exposing evidence in court: adversary (under common law) vs. inquisitorial procedure (in the civil code). Moreover, judges under common law are elected
} 
We argue that when the law is made at an ex-post stage, judges may suffer from credibility problems: the ex ante optimal ruling might be suboptimal ex post, after the parties' actions are sunk. Such an ex-post bias arises (1) because courts rule after the parties have made their economic decisions and (2) because private agents make their choices based on expected rulings by courts. Courts' credibility problems may have serious consequences on economic outcomes. To see this, consider two examples of judicial decision making that have been the focus of attention in the literature on legal origin: the enforcement of property rights and the protection of investors. In both cases, courts may have an incentive to declare strict enforcement of property rights and strong investor protection in order to induce, respectively, high investment on property and cheaper access to financing. However, absent commitment, courts may choose a weaker ruling ex post. Anticipating this behavior, rational agents would make sub-optimal decisions, such as low investment and low credit supply. ${ }^{8}$

Despite their relevance, the credibility problems induced by the ex-post bias in courts are somewhat understudied in the literature (see, however, Anderlini et al., 2014). Much more attention has been devoted to studying judicial partisan bias, which arises when courts have preferences favoring one of the two sides in the legal dispute. ${ }^{9}$ As shown in this paper (see Section 8 below), the ex-post bias and the partisan bias generate very different outcomes and implications.

Civil law partly solves credibility problems by limiting the discretion enjoyed by the courts. The statute (or code) specifies the level of property-right protection and decisions by courts must lie in an interval centered around the written statute. This assumption captures the idea that judicial discretion can be limited but cannot be completely taken away from civil law judges. The statute is written by the legislature once-and-for-all at time zero. Under common law, instead, lawmaking power has been delegated to judges, making credibility problems potentially more severe. These problems are partially solved by the rule of precedent. The fact that the two systems deal differently with courts' ex-post bias has implications in terms of relative efficiency, consistency, and of the ability of each legal system

or appointed by the executive (usually the legislative body must confirm the appointment), while under civil law there is a career judiciary with training and promotion inside the ranks.

${ }^{8}$ There are many other examples of spheres in which there is a potential time-inconsistency in judicial decisions. Consider a court that examines a patent infringement case. Ex ante, the optimal breadth of the patent takes into account the incentives to invest in R\&D. Ex post, however, it is optimal to open the market to competition. In tort law, an ex-post bias might also arise when courts apply the "economic loss rule" (see Niblett et al. 2010).

${ }^{9}$ See, for instance, Gennaioli and Shleifer (2007b) and Ponzetto and Fernandez (2008). 
to adapt to changing economic conditions.

Under civil law, we show that the statute is set by the legislature in a strategic way to offset the incentives of benevolent courts to deviate ex post. In particular, the statute is set with a different objective than the ex ante optimum, so that the ex post decision is closer to the optimum. The higher the fraction of benevolent judges, the stronger the incentive to write the code in a strategic way. Since judges can be of two types, and because the code cannot be made contingent on the type of the judge enforcing the law, the legislator faces legal uncertainty when writing the law. Given the same statute, some judges will interpret the law literally, while other judges (the benevolent ones) will reoptimize ex post. We show that civil law courts do not treat people equally, and decisions depend on the particular judge enforcing the law: judicial heterogeneity prevents legal certainty and reduces efficiency under civil law.

Under common law, the rule of precedent plays two roles. First, it serves a disciplinary role. The threat that conservative judges in the future will mechanically follow "bad" precedents, thus providing weak protection of property rights, helps to sustain the ex ante optimal policy, despite the degree of discretion that common law courts enjoy. The intuition is the following: courts' one-shot deviations from the ex ante optimal decision have lasting consequences in the common law tradition, since overruling an ex ante optimal precedent implies a change of the precedent for future courts. The disciplinary role of stare decisis is more effective when judges are forward-looking and the proportion of conservative judges is higher. ${ }^{10}$ Second, the rule of precedent helps to achieve legal certainty by linking current judicial decisions to future ones. It is commonly believed that giving discretionary power to judges undermines legal certainty. We show instead that thanks to stare decisis, all types of common law courts enforce the same decisions, making the law consistent and predictable. ${ }^{11}$

Our results show that common law is unambiguously better in achieving legal consistency than civil law. However, when comparing welfare levels under both traditions, the conclusion is not as clear-cut. On the one hand, common law welfare is close to the first-best outcome if judges are sufficiently forward-looking and if there are many conservative judges. But on the other hand, when the proportion of conservative judges is high, judicial heterogeneity is

\footnotetext{
${ }^{10}$ The rule of precedent confounds many scholars and "still demands convincing explanation" (Peters, 1996). As discussed in this paper, the inertia introduced by stare decisis is welfare-improving when judges suffer from an ex-post bias.

${ }^{11}$ Interestingly, legal certainty is often used as argument against the adoption of the rule of precedent in the civil law tradition. See Merryman (2007).
} 
reduced and civil law welfare reaches full efficiency. Our findings indicate that civil law dominates in terms of efficiency when the proportion of conservative judges is either sufficiently low or sufficiently high.

We conclude our analysis by introducing an additional source of uncertainty: shocks to the environment that change the optimal law. The goal is to study how the two legal traditions adapt to changing economic conditions. In the context of our stylized model, we find that civil law courts do not respond to shocks to the environment. The variability of legal decisions under civil law arises because of judicial heterogeneity (namely, different judges make different decisions), not because courts adapt to changing economic conditions. Conversely, the common law regime innovates, but it proceeds by "slow advances". Because of the inertia introduced by the rule of precedent, common law courts are cautious in changing the precedent when facing a shock because they are afraid that in the next period — when a new shock occurs - this new precedent may not be justified. With respect to the "size" of the adjustment, what matters is the persistence of the shock (common law courts change the law by a smaller amount after a temporary shock) and the proportion of judges that strictly apply the rule of precedent (if this proportion is high, the expected inertia of common law is stronger and current adjustments are smaller as a result). When economic shocks are independent over time, common law courts are completely unresponsive to economic shocks, similarly to civil law courts. We find that when shocks are more persistent, expected welfare under common law is strictly higher because of its greater adaptability than welfare under civil law for a larger range of parameters.

The remainder of the paper is organized as follows. Section 2 reviews the literature. The model is introduced in Section 3. Section 4 and 5 solve the model under common law, and under civil law. In Section 6 we compare the two regimes. In Section 7 we analyze how the two legal traditions react to changing economic conditions. Section 8 studies a model with judicial partisan bias, and Section 9 concludes.

\section{Literature Review}

The hypothesis that common law is efficient (and, possibly, superior to civil law) has been widely investigated by the literature on law and economics. According to Posner (2003), the most influential scholar to endorse this view, judge-made laws are more efficient than statutes, 
mainly because courts, unlike legislators, have personal incentives to maximize efficiency. ${ }^{12}$ Evolutionary models of common law have called attention to explanations other than judical preferences. For instance, it has been argued that case law moves towards efficiency because inefficient rules are more often (Priest, 1977, and Rubin, 1977) or more intensively (Goodman, 1978) challenged in courts than efficient ones. Gennaioli and Shleifer (2007b) build a model of precedent formation by appellate courts and show that common law evolves towards better legal rules only under special conditions. In their model, the evolution of precedents is driven by judicial partisan bias, and new information is added as precedents evolve. The intuition for this result is that polarized judges have stronger incentives to distinguish the existing precedent in order to correct the bias of the previous court. ${ }^{13}$ More recently, Gennaioli and Ponzetto (2015) consider a model in which they study the two-way feedback loop between legal rules and the economy. In their model, contract incompleteness is a function of current precedents. At the same time, precedents are affected by the contracts which have been brought to court. Compared to them, the interactions between the economy and the legal rule are simplified in the present paper in order to focus on the comparison between common law and civil law. In a fully dynamic model where courts have to spend time and resources investigating a case, Backer and Mezzetti (2012) find that precedents might converge to an inefficient set of legal rules. ${ }^{14}$ Fon and Parisi (2006) study the dynamics of precedents under civil law. In their model, statute law courts take past decisions into account when there is a sufficient level of consistency in past judicial decision ("jurisprudence constante"). ${ }^{15}$

Similarly to us, other papers have explicitly compared judge-made laws and statutes. In a pioneering paper, Glaeser and Shleifer (2002) analyze common law (independent juries) and civil law (bright line rules) in a static model with particular emphasis on the ability of each system to control law enforcers. Ponzetto and Fernandez (2008) compare case law and statute law in a dynamic setting with a focus on the evolution of precedents and statutes over time. In a model where judges have idiosyncratic preferences and overruling is costly, they show that case law converges to an asymptotic distribution with mean equal to the efficient

\footnotetext{
${ }^{12}$ In Hadfield (1992), however, efficiency-oriented courts may fail to make efficient rules because of the bias in the sample of cases observed by courts.

${ }^{13}$ Judicial bias is interpreted in a broad sense that ranges from "idiosyncracies" in the judges' preferences (Bond, 2009, Gennaioli and Shleifer, 2007b) to plain "corruption" of the courts (Ayres, 1997, Bond, 2008, Legros and Newman, 2002, among others).

${ }^{14}$ See also Callander and Clark (2016) who study common law dynamics in a model with judicial learning.

${ }^{15}$ The implications of either persuasive or binding precedents on the courts' incentives to acquire information have been recently studied by Chen and Eraslan (2016).
} 
rule. In the long run, as precedents become more consistent, case law eventually dominates statute law by making better and more predictable decisions.

Aside from a variety of modeling choices, one key difference between Ponzetto and Fernandez (2008) and our work is our focus on the potential time-inconsistency generated by ex post courts' intervention. Compared to judicial bias, the present-bias temptation has quite different implications in terms of dynamics of precedents. Moreover, a central ingredient of our model of the case law regime is the disciplinary role of stare decisis. In Ponzetto and Fernandez (2008), the rule of precedent has ambiguous welfare predictions: strong adherence to previous decisions slows down the convergence to the efficient rule, but it implies less variability in the long run. However, when judges are assumed to be forward looking (as it is always the case in our paper), the rule of precedent induces more extremism, which is welfare reducing. In Gennaioli and Shleifer (2007a), for a given level of judicial polarization, welfare in case law is independent of the strength of stare decisis, as measured by the cost of overruling the precedent.

We also ignore the distinction between "lower" and "appellate" courts. As in Gennaioli and Shleifer (2007b), strictly speaking all common law courts in our model should be viewed as appellate courts since they have the ability to change the state of precedents. ${ }^{16}$

The disciplinary role of stare decisis has been first pointed out by Anderlini et al. (2014). This paper differs from Anderlini et al. (2014) in several respects. First, this paper proposes a model of the civil law regime, while Anderlini et al. (2014) focuses exclusively on the common law regime. Second, this paper simplifies the rule of precedent so as to avoid some of the complications of Anderlini et al. (2014). In particular, in the latter paper the common-law equilibrium is generally in mixed strategies. By simplifying the precedent technology we are able to consider a continuum of judicial policies, while in Anderlini et al. (2014) the law only takes two values. Third, in Anderlini et al. (2014) courts' payoffs were exogenously given, while in this paper they are microfounded by a having a simple model of investment decisions. Fourth, compared to Anderlini et al. (2014), our focus is not only on legal efficiency, but also on legal consistency. Finally, in this paper we study the adaptability of each legal system to economic shocks. ${ }^{17}$

\footnotetext{
${ }^{16}$ The efficiency rationale for the existence of an appeal system has also received vigorous scrutiny in recent years (Daughety and Reinganum, 1999, 2000, Levy, 2005, Shavell, 1995, Spitzer and Talley, 2000, among others), but its differential impact in the case and statute law regimes is far from obvious, both theoretically and empirically.

${ }^{17}$ See also Anderlini et al. (2013) for the analysis of the implications of full discretion and commitment to
} 
Finally, this paper is also related to a recent political economy literature which endogeneizes property rights and studies the relation between the political structure and the extent of property right protection. Acemoglu (2009, chapter 22) and Besley and Ghatak (2010) study property right enforcement in the presence of a commitment (or holdup) problem that is similar to the one studied here. In the context of a model of elite-dominated politics, Acemoglu (2009) shows that the elite may wish to change economic institutions to provide additional property rights protection to producers. ${ }^{18}$ In a seminal paper, North and Weingast (1989) argue that the establishment of checks and balances improved the protection of property rights. More recently, Diermeier et al (2015) surprisingly find that strengthening the amount of checks and balances may result in greater expropriation.

\section{The Model}

We build a stylized model to capture the courts' trade-off between providing incentives and ex post efficiency. Time is infinite and indexed by $t, t=0,1, \ldots, \infty$. The economy includes the following agents: two short-lived private agents $(A$ and $B$ ) and a continuum of longlived courts, distributed over an interval $[0,1]$ of jurisdictions. In the civil law model there is another player, the legislator, whose task is to write the statute (or code) that will be enforced by the courts.

Private Parties. During each period $t$, agents $A$ and $B$ are born in one jurisdiction at random. Parties $A$ and $B$ live one period. We suppose that party $A$ has the possibility to make a costly and non-contractible investment $e \in[0, \bar{e}]$. As discussed below, the investment directly increases $A$ 's payoff and has a positive externality on $B$. After $A$ has chosen $e$, the court intervenes by making a decision $p \in[0, \bar{p}]$ that affects both parties. Suppose $\bar{p}=\bar{e}$. Our setting is sufficiently general to admit several interpretations. For example, the parameter $p$ could represent the level of property rights protection that is enforced in the economy. According to this interpretation, $p=\bar{p}$ would stand for an absolute property right, while $p=0$ would imply that property is expropriated. ${ }^{19}$

an incomplete law in an endogenous growth model with vertical innovations.

${ }^{18}$ See also Cervellati et al (2007) who study the joint determination of political regimes (democracies vs oligarchies) and property right protection.

${ }^{19}$ See Levine (2005) for a review of the literature on law and property rights. There is a large body of literature that analyzes conditions under which the allocation of property rights restores efficiency in models where private agents lack commitment (see, for instance, Maskin and Tirole, 1999). This literature, however, assumes that benevolent courts have commitment. 
To obtain closed-form solutions, we assume the following utility functions for $A$ and $B:^{20}$

$$
\begin{aligned}
& u_{A}(e, p)=p e-\frac{1}{2} e^{2}, \\
& u_{B}(e, p)=-p^{2}+e z .
\end{aligned}
$$

Notice from the first term of (1) that investment is beneficial for $A$. The second term of (1) is the quadratic cost of investment. From (2), the utility of party $B$ is decreasing in $p$ (the first term) and increasing in $A$ 's investment (the second term). The parameter $z \in[0, \bar{p} / 2]$ measures the importance of the externality on $B$.

To motivate payoffs (1) and (2), suppose that $A$ is the owner of a plot of land. Party $A$ chooses the amount of investment $e$ on his plot. Imagine that the investment has a positive externality on individual $B$. Moreover, the utility of $B$ increases when the property right of $A$ decreases, possibly because $B$ would like to have the right to pass through $A$ 's land.

The role of courts is to choose $p$. Whether or not parties actually go to court is not essential for our arguments. The level of property right protection that is observed in the economy is the one that judges would choose if parties had gone to court. If this were not the case, given that the two parties have opposite preferences about $p$, and provided that going to court is not costly, one of the two parties would bring the other to court.

Courts. Each jurisdiction is run by one judge. Judges can be of two types. A fraction $\gamma$ of judges, with $\gamma \in[0,1]$, are conservative: they make decisions in a mechanical way. Conservative judges are judges that strictly follow the precedent (under common law) or the statute (under civil law). There are different reasons why judges do not operate in a substantive way (i.e., by creating and defining rights and duties). Judges are conservative either because they adhere to legal formalism (i.e., they believe that the law consists of a body of rules and judges have no authority to act outside these rules), because there might be some cost (e.g, career concerns) of deviating from the code or precedent, or because judges follow simple behavioral rules. ${ }^{21}$

A fraction $1-\gamma$ of judges are benevolent judges: their per-period utility is given by the

\footnotetext{
${ }^{20}$ The thrust of our results would hold under more general specifications.

21 "[When judges] are trained to think in mechanical and doctrinal rather than functional and substantive terms, mental habits are developed that stand in the way of the perception requisite to a truly functional approach." Von Mehren, (1957, p. 825).
} 
following welfare function:

$$
W(e, p)=\theta u_{A}+(1-\theta) u_{B}
$$

with weights $\theta \in[0,1]$. Since judges are forward-looking, the intertemporal utility from time $t$ onwards is

$$
\sum_{j=t}^{\infty} \delta^{j-t} W\left(e_{j}, p_{j}\right)
$$

where $\delta \in[0,1)$ is the discount factor. Benevolent judges believe in legal instrumentalism: i.e., their view is that the law should be used as a tool to balance competing societal interests.

We assume that the proportion $\gamma$ is the same under common law and civil law.

Legislator. In civil law, the code is written at the beginning of time 0 , once and for all. We suppose that the legislator is benevolent, with the welfare criterium given by (4). The assumption that legislatures and benevolent judges share the same preferences constitutes a useful benchmark. Moreover, we believe that this assumption is not far-fetched, especially under common law where judges are elected or appointed by politicians. Along the same lines, Cardozo writes: "Substitute statute for [judicial] decision, and you shift the center of authority, but add no quota of inspired wisdom." ${ }^{22}$

Within each period $t$, the timing of the game is as follows. At the beginning of the period, party $A$ first chooses investment $e$ and, second, the court chooses $p$ subject to the institutional constraints that are specific to the legal regime (see Sections 4 and 5).

To solve for the equilibrium, we make the following two assumptions. First, we assume that private parties know the type of court (whether benevolent or conservative) in their jurisdiction. Consequently, $A$ and $B$ foresee the level of property right protection that will be enforced. This assumption is not essential, but allows us to obtain simple closed-form solutions. Second, we assume that party A takes the courts' enforcement policy as given. This assumption is done in virtually all macroeconomics models, where it is commonly assumed that in choosing consumption or savings, each private agent takes public policies as given and does not internalize the effect of her decisions on the government. ${ }^{23}$ In particular, we assume

\footnotetext{
${ }^{22}$ Cardozo (1924, p. 133).

${ }^{23}$ The notion of rational expectations equilibrium used here is described, for instance, in Stokey (1989) and Ljungqvist and Sargent (2012, p. 940).
} 
here that party $A$ does not internalize the effect of $e$ on the court's decision. ${ }^{24}$

To reduce the multiplicity of equilibria, in this paper, we restrict judges and agents to use Markov strategies. Finding the equilibrium amounts to solving for a fixed-point problem. (i) Given the courts' enforcement policies, party $A$ chooses $p$ to maximize (1). (ii) Conservative courts mechanically follow the law that is specified in the code or in the precedent. (iii) Benevolent courts maximize (4) subject to the institutional constraints of the legal regime in which they operate (to be discussed shortly). (iv) As in a rational expectation equilibrium, the investment decision by $A$ must be consistent with actual decisions by the courts (and vice versa).

\subsection{Two Benchmarks: Commitment vs No Commitment}

We begin this section by deriving the investment rule of party $A$. As discussed above, $A$ takes the court's enforcement policy as given and observes the court's type. Given $A$ 's expectation about $p, A$ 's investment decision solves the following problem:

$$
\max _{e \in[0, \bar{e}]} p e-\frac{1}{2} e^{2}
$$

It is straightforward that optimal investment by $A$ is:

$$
e^{*}=p
$$

That is, optimal investment by $A$ coincides with the expected law. The higher $p$ (e.g., the more secure property rights are), the higher $A$ 's investment. Expression (6) is the key channel through which the courts affect economic outcomes in our model.

In the rest of this section we study two benchmarks. The first is the model with full commitment, while the second is the one-shot model without commitment. ${ }^{25}$

Commitment. We analyze the ex ante optimal decision $p^{*}$ made by a benevolent lawmaker. Since the economy is of the repeated type, $p^{*}$ is constant over time.

Under commitment, the law-maker correctly internalizes that the law affects $A$ 's invest-

\footnotetext{
${ }^{24}$ This assumption is particularly intuitive if there is a continuum of private agents. Our setting could easily be adapted to allow for a continuum of agents without changing the results.

${ }^{25}$ The first model is often denoted as the "Ramsey problem", while the "no commitment model" corresponds to the Nash equilibrium in Ljungqvist and Sargent (2012, p. 942).
} 
ment via (6) and solves:

$$
\max _{p \in[0, \bar{p}]} \theta\left(\frac{p^{2}}{2}\right)+(1-\theta)\left(-p^{2}+p z\right) .
$$

Noticing that the objective in (7) is concave in $p$ when $\theta \leq 2 / 3$ and is convex (and increasing) when $\theta \geq 2 / 3$, we can state without proof the following result.

Proposition 1. [First-best] The ex ante optimal law is

$$
p^{*}=\left\{\begin{array}{c}
\min \left\{z \frac{1-\theta}{2-3 \theta}, \bar{p}\right\} \text { if } \theta \leq 2 / 3 \\
\bar{p} \text { otherwise }
\end{array}\right.
$$

For instance, when $\theta=1 / 2$, the optimal law is $p^{*}=z$. A few remarks are in order. First, note that even when the law-maker only cares about party $B$ (i.e., $\theta=0$ ), the optimal law is not full expropriation since, by (6), this would induce zero investment. The ex-ante optimal law increases in $\theta$, the weight attached to party $A$. This is intuitive: since $A$ prefers high values of $p, p^{*}$ obviously increases when $\theta$ is higher. Second, the optimal law is increasing in $z$. When the externality is larger, the court chooses higher $p$ in order to give $A$ stronger incentives to invest.

No commitment. We consider a one-shot game and we solve for the equilibrium without commitment. Since the game is sequential (with $A$ moving first and the court moving second) we use backward induction. We begin considering the court's problem. Given e, the lawmaker solves

$$
\max _{p \in[0, \bar{p}]} \theta\left(p e-\frac{1}{2} e^{2}\right)+(1-\theta)\left(-p^{2}+e z\right)
$$

From the first order condition, it is straightforward that the ex post court's rule is

$$
p^{e x}=\min \left\{\frac{\theta}{2(1-\theta)} e, \bar{p}\right\}
$$

Note from (10) that if $A$ does not invest, the court ex-post chooses low property right protection. When $e=0$, the utility of $A$ is zero and does not depend on $p$. The court will therefore choose $p=0$ to raise $B$ 's utility. The higher $e$, the higher the ex-post optimal law. The slope of the court's ex post rule depends on $\theta$ : when $\theta<2 / 3$ (resp. $\theta>2 / 3$ ) the slope of the ex 
post rule is smaller (resp. larger) than 1.

Figure 1:

$$
\theta<2 / 3
$$

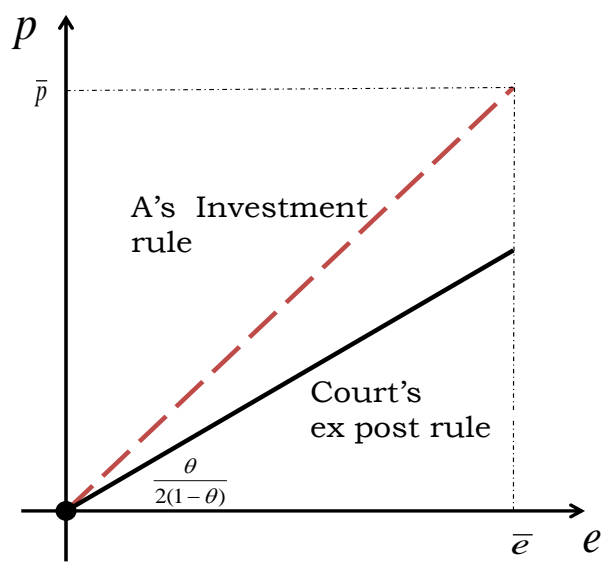

Figure 2:

$\theta>2 / 3$

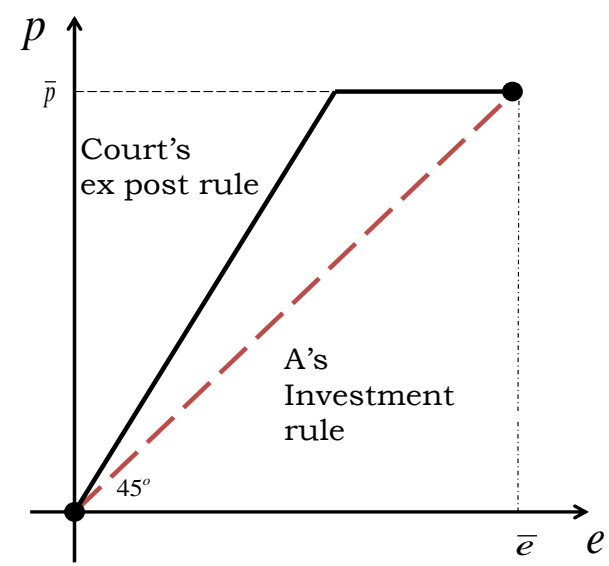

Proceeding backward, the investment decision in the first stage is given by expression (6). The equilibrium of the game can be studied graphically. In Figures 1 and 2 we depict the ex post rule (10) and the investment rule (6) in the space $(e, p)$. The investment rule coincides with the 45 degree line. In equilibrium, investment must be consistent with expected enforcement: the two rules must intersect. By looking at Figures 1 and 2, it is immediate to state the following Proposition.

Proposition 2. [No commitment] The equilibrium outcome $\left(e^{n}, p^{n}\right)$ of the one-shot game without commitment is $(0,0)$ when $\theta \leq 2 / 3$. When $\theta \geq 2 / 3$ there are two equilibria: $(\bar{p}, \bar{p})$ and $(0,0)$.

We can compare the solution under commitment (Proposition 1) to the one without commitment (Proposition 2). Two cases must be considered. First, when $\theta \leq 2 / 3$, no commitment leads to zero investment (see Figure 1), while commitment induces positive investment. The result that lack of commitment induces underinvestment is intuitive. Since $A$ 's investment has a positive externality on $B$, investment is suboptimally low from the perspective of the society. Therefore, the ex ante optimal law prescribes strong property right protection to induce $A$ to invest. However, once investment has been made, the courts have an incentive to choose weaker property right protection. Since $A$ is aware of the courts' incentives, $A$ 's investment ends up being inefficiently low. Notice that the existence of an externality from $A$ 's investment to B's utility is crucial to have credibility problems. Without 
this externality (i.e., when $z=0$ ), the court does not disagree with $A$ about the optimal level of investment: the ex post law coincides with the optimal one. To see this analytically, observe that when $z=0$ and after using the first-order condition of A's problem (5), the optimality conditions of problems (7) and (9) coincide.

The second case is when $\theta \geq 2 / 3$. Figure 2 shows that there are multiple equilibria in the game without commitment. If we focus on the "best" equilibrium, namely $(\bar{p}, \bar{p})$, investment with or without the courts' commitment is identical. If instead we pick the "bad" equilibrium $(0,0)$, lack of commitment leads to strictly lower investment.

Throughout, we focus on the most "interesting" case: when lack of commitment leads to severe under-investment. In addition, we suppose that $\bar{p}$ is sufficiently large that for all $\theta \mathrm{s}$ considered in this paper, the first-best law is feasible. We let $p^{\star}(\theta)$ denote the first-best law that corresponds to a particular welfare weight.

Assumption 1: Suppose $\theta \in[0, \bar{\theta}]$ where $\bar{\theta}<2 / 3$. Moreover, for all $\theta \in[0, \bar{\theta}]$, we require that $p^{\star}(\theta)<\bar{p}$.

For future use, we introduce the parameter $\zeta$, defined as $\zeta \equiv \bar{p}-p^{\star}(\bar{\theta})$. When Assumption 1 holds, $\zeta$ is strictly positive.

In the following sections, we will describe how the two legal systems improve, at least from a social perspective, upon the institution-free equilibrium without commitment.

\section{Civil Law}

At the beginning of $t=0$ a benevolent legislature writes the code (or statute), denoted by $l_{s} \in[0, \bar{p}]$, once and for all. The statute is written under the veil of ignorance, without knowing the type of judges who will make decisions in each period. As before, we suppose that in each period, party $A$ chooses investment first and later the courts enforce the law. 
Conservative courts strictly follow the code and, consequently, $p=l_{s}$. Benevolent civil law courts are not entirely bound by the code, but they have some limited amount of discretion in interpreting the law. More precisely, they must choose $p$ in the interval $\left[l_{s}-\varepsilon, l_{s}+\varepsilon\right]$. The parameter $\varepsilon>0$ is a measure of the courts' latitude in interpreting the statute. To insure that the optimal code is at the interior of $[0, \bar{p}]$, we require that $\varepsilon$ is not too large. In particular, for any given $\theta$, we suppose $\varepsilon<p^{\star}(\theta)$ and $\varepsilon<\zeta$. The parameter $\varepsilon$ might be related to the specific issue discussed in the law (e.g., ambiguous matters may give judges more discretion) or the the capacity of the legislative and executive branches to control the judicial branch.

\section{Figure 3}

\section{Civil Law}

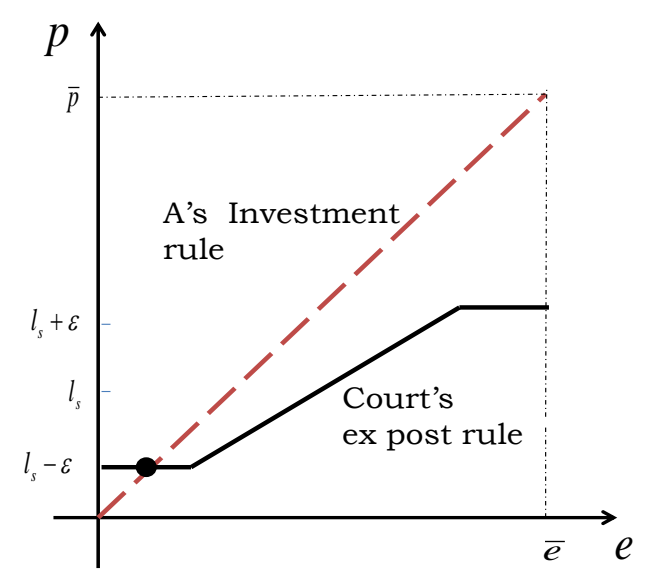

Benevolent court ex-post decision. The benevolent court's problem is de facto a static problem because under civil law there is no dynamic linkage across periods. Given $l_{s}$, benevolent courts choose $p$ to maximize ex post payoff subject to the loose constraint imposed by the code:

$$
\max _{p \in\left[l_{s}-\varepsilon, l_{s}+\varepsilon\right], p \in[0, \bar{p}]} \theta\left(p e-\frac{1}{2} e^{2}\right)+(1-\theta)\left(-p^{2}+e z\right) .
$$

It is easy to obtain that the ex-post rule of a benevolent court is increasing and piecewise linear in $e$ (see the Appendix). When $e$ is either sufficiently low (resp. sufficiently high) the court's reaction function is flat because the constraint $p \geq l_{s}-\varepsilon$ (resp. $p \leq l_{s}+\varepsilon$ ) is binding (see Figure 3 below). As before, the equilibrium is given by the intersection of the ex post court's rule with the investment rule.

Lemma 1. Let Assumption 1 hold and any $l_{s} \in[0, \bar{p}]$ be given. When a benevolent judge 
decides, the equilibrium outcome in each $t$ is equal to $\left(l_{s}-\varepsilon, l_{s}-\varepsilon\right)$ when $l_{s}>\varepsilon$ and $(0,0)$ when $l_{s} \leq \varepsilon$.

The intuition for Lemma 1 is straightforward: judges have an ex post incentive to choose weaker property right protection than from an ex ante perspective. The constraint imposing that $p \geq l_{s}-\varepsilon$ is binding for low values of $e$. Since $A$ correctly foresees the courts' behavior, $A$ chooses $e=l_{s}-\varepsilon$.

Optimal Code. The legislator writes the statute at $t=0$ knowing that with probability $\gamma$ the court will follow $l_{s}$, but with probability $1-\gamma$ the court will optimize. It can be shown (see the Appendix) that given our parameter restrictions, the legislator does not find it profitable to set the code below $\varepsilon$. Therefore, using Lemma 1 we write the legislator's problem as follows:

$$
\max _{l_{s} \in[0, \bar{p}]} \gamma W\left(l_{s}, l_{s}\right)+(1-\gamma) W\left(l_{s}-\varepsilon, l_{s}-\varepsilon\right),
$$

or, using (3),

$$
\max _{l_{s} \in[0, \bar{p}]} \gamma\left[\theta\left(\frac{l_{s}^{2}}{2}\right)+(1-\theta)\left(-l_{s}^{2}+l_{s} z\right)\right]+(1-\gamma)\left[\theta\left(\frac{\left(l_{s}-\varepsilon\right)^{2}}{2}\right)+(1-\theta)\left(-\left(l_{s}-\varepsilon\right)^{2}+\left(l_{s}-\varepsilon\right) z\right)\right] .
$$

It is immediate to find the optimal statute for extreme values of $\gamma$. When $\gamma$ is either zero or one, civil law reaches full efficiency. If $\gamma=1$ (all courts are conservative), the optimal statute prescribes $l_{s}=p^{*}$, which is enforced by all judges. If $\gamma=0$ (all courts are benevolent), the civil law implements the optimal law by overshooting and setting $l_{s}=p^{*}+\varepsilon$.

If $\gamma \in(0,1)$, welfare under civil law is below the first-best level. In this case, the legislature optimally sets the law between $p^{*}$ and $p^{*}+\varepsilon$. The solution of problem (13) has a simple expression:

Proposition 3. [Civil Law] Under civil law, the code is optimally set above the first-best law:

$$
l_{s}=p^{\star}+(1-\gamma) \varepsilon
$$

where $p^{\star}$ is defined in Proposition 1. 
Notice that the enforced law alternates between $l_{s}$ (with probability $\gamma$ ) and $l_{s}-\varepsilon$ (with probability $1-\gamma)$. Judicial heterogeneity leads to legal inconsistency: similar cases are treated differently.

It is interesting to note that, at least in expectation, the enforced level of property-right protection coincides with the efficient outcome. In fact, the expected law is given by

$$
E(p)=\gamma l_{s}+(1-\gamma)\left(l_{s}-\varepsilon\right)=p^{\star}
$$

However, when $\varepsilon>0$ and $\gamma \in(0,1)$, the optimal decision $p^{*}$ is never implemented under civil law. In equilibrium, conservative (resp. benevolent) judges enforce property right protection above (resp. below) the optimal level.

We support our claim that statutes are written in anticipation of the application of the law by looking at the conception of property rights in the French legal system. The French Napoleonic Code's idea of property was inspired by the naturalistic ideology. Article 544 famously states that ownership is the right to use and dispose of property in the most absolute way. In the French revolutionary reform program, having individual sovereignty over property was regarded as the most effective barrier against the unrestricted power of the state. The natural law idea of property was soon challenged because of the likely antisocial consequences of having absolute property rights when there are externalities. However, the French Code kept proclaiming an absolute proprietary freedom, but French courts escaped from a literal interpretation of the Code. Comparing nuisance laws in France and England, Weir writes:

"French law initially gives a broad right by statute and then restricts its antisocial use by the courts; in England, when it is the courts who announce the rights, they do it so very restrictively that there is little need for an equitable temperance of their exercise." 26

This suggests that the law often sets stricter rules than the ex ante optimum, so that the ex post courts' decisions are closer to the optimum.

\section{Common Law}

Common law does not "tie the hands" of the judges. We suppose instead that judges can make any decision $p$ in the entire interval $[0, \bar{p}]$. In other words, the current precedent per se

\footnotetext{
${ }^{26}$ Weir in Catala and Weir (1964) at p. 238.
} 
does not affect the set of feasible judgements. ${ }^{27}$ Even if judges are free to choose any policy in the set $[0, \bar{p}]$, in this section we show that common law judges optimally choose not to contradict previous precedents.

Benevolent common law courts play a dynamic game as they realize that their decision will affect future investment and legal decisions. We focus on Markov perfect equilibrium and rule out history dependent strategies (see Maskin and Tirole, 2001, for a justification). The state variable in the investment problem by $A$ includes the current precedent, which is denoted by $p_{-1} \in[0, \bar{p}]$. The current precedent is the law that was chosen in the previous period. The strategy for party $A$ when a benevolent judge is expected to make decisions is denoted by the function $\Phi:[0, \bar{p}] \rightarrow[0, \bar{e}]$, which associates an investment level with the current precedent. When a conservative judge is deciding, the investment strategy is denoted by $\Phi^{C}:[0, \bar{p}] \rightarrow[0, \bar{e}]$

Common law courts intervene ex post. Therefore, the state variable when a benevolent judge decides is $\left(p_{-1}, e\right)$. The current decision $p$ will become the new precedent in the next period. The problem of the conservative court is trivial, as it confirms the current precedent in a mechanical way. Using (6), this implies that $\Phi^{C}(p)=p$. A strategy for a benevolent judge is represented by the function $G:[0, \bar{p}] \times[0, \bar{e}] \rightarrow[0, \bar{p}]$, which associates a new decision with a precedent and an investment decision.

The problem of a benevolent court can be formulated as a Bellman equation:

$$
V\left(p_{-1}, e\right)=\max _{p \in[0, \bar{p}]}\left\{W(p, e)+\delta(1-\gamma) V(p, \Phi(p))+\delta \gamma V^{C}\left(p, \Phi^{C}(p)\right)\right\}
$$

with

$$
V^{C}\left(p, \Phi^{C}(p)\right)=W\left(p, \Phi^{C}(p)\right)+\delta(1-\gamma) V(p, \Phi(p))+\delta \gamma V^{C}\left(p, \Phi^{C}(p)\right)
$$

where $V^{C}$ is the value function of a benevolent judge when a conservative judge enforces the law. Note that in each period, the benevolent judge does not know which judge will enforce the law in the next period. This explains why her continuation payoff is a weighted sum of two continuation utilities, $V^{C}$ and $V$, with weights given by the fraction of conservative and benevolent judges, respectively.

\footnotetext{
${ }^{27}$ Indeed, up until now not a single judge has ever been impeached for not following a precedent, even when the precedent was from a superior court.
} 
The court's trade-off is intuitive. On the one hand, after the investment by $A$ is sunk, the benevolent court wants to weaken property right protection if it looks only at today's payoff, but if it looks forward, via precedents, it wants to make the optimal decision. The higher the proportion of conservative judges, the higher the cost of choosing weak property right protection. In particular, the larger the $\gamma$, the longer the economy will be subject to a "bad" precedent. Having a high ratio of conservative judges helps sustain the optimal outcome under common law because it prolongs the cost of a deviation from the ex ante optimal decision.

After solving for $V^{C}\left(p, \Phi^{C}(p)\right)$ in $(17)$, we can rewrite the Bellman equation as

$$
V\left(p_{-1}, e\right)=\max _{p \in[0, \bar{p}]}\left\{W(p, e)+\frac{\delta \gamma}{(1-\delta \gamma)} W\left(p, \Phi^{C}(p)\right)+\frac{\delta(1-\gamma)}{(1-\delta \gamma)} V(p, \Phi(p))\right\}
$$

The envelope condition is given by

$$
V^{\prime}\left(p_{-1}, \Phi\left(p_{-1}\right)\right)=(1-\theta) z \Phi^{\prime}\left(p_{-1}\right)
$$

Thus, using (3) and (19), and knowing that $\Phi^{C}(p)=p$, the first order condition of a benevolent court is given by

$$
[\theta e+(1-\theta)(-2 p)]+\frac{\delta \gamma}{1-\delta \gamma}[\theta p+(1-\theta)(z-2 p)]+\frac{\delta(1-\gamma)}{(1-\delta \gamma)}(1-\theta) z \Phi^{\prime}(p)=0
$$

The first term is the ex-post temptation to make a "weak" decision. The second term represents the cost of having a "bad" precedent after the deviation. The third term depends on how the investment of party $A$ reacts to a change of precedent. We conjecture and later verify an equilibrium in which benevolent judges, starting from any precedent, make the same decision. ${ }^{28}$ This implies that $\Phi^{\prime}(\cdot)=0$, since party $A$, expecting that benevolent courts will follow the posited strategy profile, makes a constant investment for all precedents. We can therefore simplify (20) by removing the third term of the LHS. Thus, we can solve for the court's rule:

$$
p^{e x}=\frac{z \delta \gamma(1-\theta)}{2(1-\theta)-\gamma \theta \delta}+\frac{\theta(1-\gamma \delta)}{2(1-\theta)-\gamma \theta \delta} e .
$$

\footnotetext{
${ }^{28}$ This is a natural guess given that past precedents do not affect the set of feasible judgments of benevolent courts.
} 
The court's ex post rule (21) is increasing in $e$ and has a positive intercept. When $e=0$, notice that the courts do not choose the static ex post optimum, which is equal to $p=0$, but, provided that $\gamma \delta>0$, they choose a positive $p$ in order to improve the future precedent. In Figure 4 we draw the ex post optimal law for the utilitarian case.

Figure 4

Common Law: $\theta=0.5$

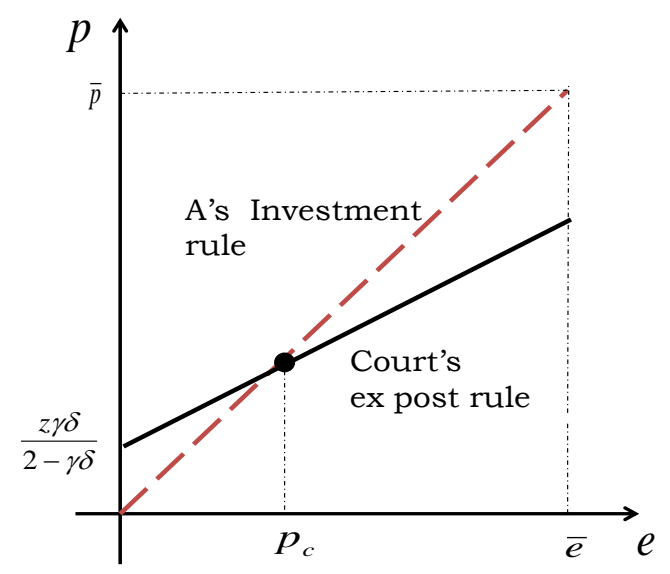

As before, the equilibrium law is at the intersection between the investment rule (6) and the court's reaction function (21). We state without proof the following Proposition:

Proposition 4. [Common Law] Under common law, for all $p_{-1} \in[0, \bar{p}]$ benevolent judges select

$$
p_{c}=z \delta \gamma \frac{1-\theta}{2-3 \theta}
$$

As soon as a benevolent court makes legal decisions, the precedent settles to $p_{c}$. Note that as $\delta \gamma \rightarrow 1$ the law under common law converges to the optimal one. However, to the extent that $\delta<1$, common law is bounded away from efficiency. In the long run, thanks to stare decisis, legal decisions are fully consistent over time.

Note that high values of $\gamma$ are associated with higher investment levels and higher expected welfare. When there are more conservative judges, the rule of precedent is more effective and the ex-post bias is reduced. Some readers may object that if most judges are conservative, it takes more time to reverse a "bad" initial precedent at $t=0$. One could consider that in 
the first period zero all judges are benevolent because there is no previous ruling on which to base the current decision. The concern that high values of $\gamma$ might lengthen the transition to the efficient rule will be relevant when we suppose that there are shocks to the optimal law (see Section 7).

The importance of the rule of precedent in explaining financial development and removing obstacles to firm performance and growth has been emphasized by Beck et al. (2003a, 2005). The authors argue that the degree to which judicial decisions are a source of law is more crucial than judicial independence in explaining cross-country differences along those two dimensions. In their views, this is so because case law is more adaptable than statutory law (on this, see Section 7). This paper, by pointing out the disciplinary role of stare decisis, provides a complementary explanation for these findings.

\section{Common Law vs Civil Law: Efficiency and Consistency}

In this section, we compare common law and civil law along two dimensions of interest: the consistency of legal decisions and overall efficiency in both legal traditions. To simplify the algebra, we henceforth make the assumption that $\theta=1 / 2$.

Concerning the variability of legal decisions, notice that common law courts eventually treat equal people equally and make the same decisions. Under civil law, however, the law is not applied uniformly and there is variability of legal decisions. These results are consistent with the empirical findings of Djankov et al. (2003), who argue that common law courts are more consistent than civil law courts.

Result 1: [Consistency] Common law is more consistent than the civil law.

To consider the relative efficiency of the two regimes, we compute the expected welfare in both legal systems. In Figures 5 and 6 we draw the welfare under common law assuming, as we discussed in the previous section, that at $t=0$ - when there is no previous precedent on which to base the current decision - all judges are benevolent. 
Figure 5

Welfare: High $\varepsilon$

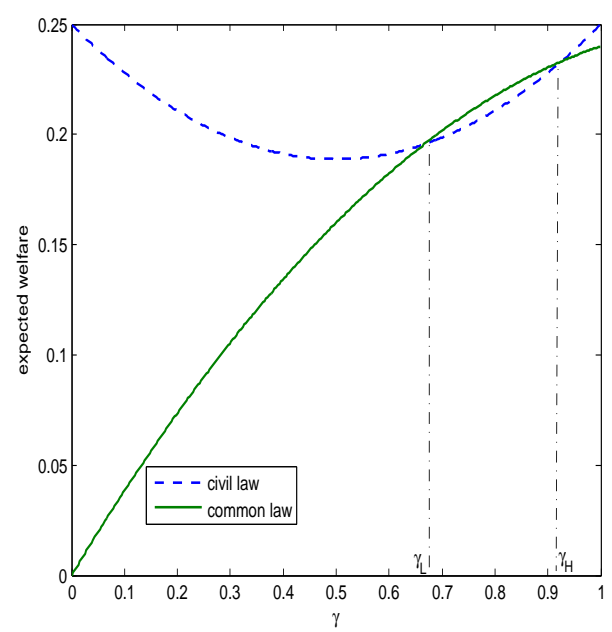

Figure 6

Welfare: Low $\varepsilon$

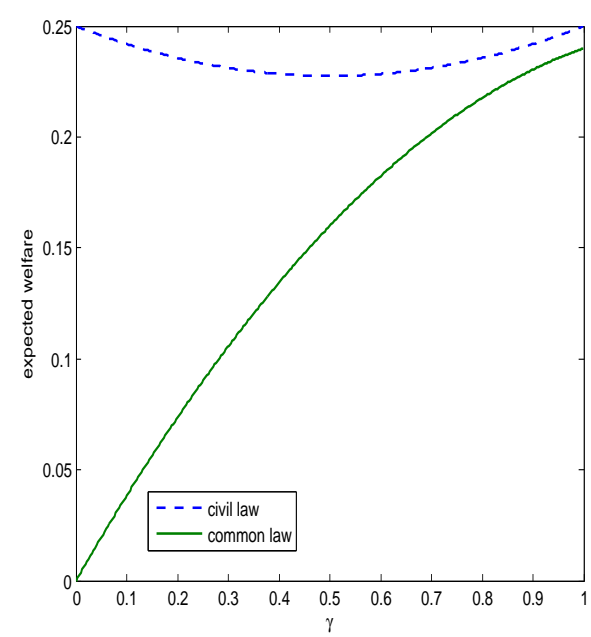

Welfare under civil law is non-monotone in $\gamma$ : it reaches full efficiency when $\gamma=0,1$ and it is at its minimum when judicial heterogeneity is maximal, $\gamma=1 / 2$. Judicial independence (measured by $\varepsilon$ ) is welfare reducing, since it increases credibility problems when a benevolent judge decides and induces the legislature to increase $l_{s}$ compared to $p^{*}$, which is costly when a conservative judge decides.

Common law can be quite far from the optimum, but at least it is consistent and treats similar people similarly. Notice that welfare under common law is increasing in $\gamma$. However, to the extent that the discount factor is less than 1, common law is bounded away from full efficiency (see also Anderlini et al. (2014)).

We show that if judicial latitude is sufficiently broad, welfare under common law is strictly above welfare under civil law when $\gamma$ is not too large but not too small either (see Figure 5). When instead $\varepsilon$ is sufficiently low, civil law strictly dominates (see Figure 6). The following Proposition provides a simple characterization of the conditions under which one regime is preferable to the other.

Proposition 5. [Welfare Comparison] Suppose $\theta=1 / 2$. When $\varepsilon<2 z \sqrt{1-\delta}$, civil law strictly dominates common law. When instead $\varepsilon \geq 2 z \sqrt{1-\delta}$, common law dominates the civil law when $\gamma \in\left(\gamma_{L}, \gamma_{H}\right)$, where $0<\gamma_{L}<\gamma_{H}<1$.

The expressions for $\gamma_{L}$ and $\gamma_{H}$ are given in the Appendix. Notice that a higher discount factor makes it less likely that civil law always dominates and, more surprisingly, that a higher 
$z$ raises the likelihood that civil law dominates. The reason why $\gamma_{H}<1$ is that when $\gamma=1$ the civil law achieves the first-best optimum, but not common law.

One might wonder whether there exists a trade-off between legal consistency and efficiency. In the model analyzed so far, the answer is negative.

Result 2: [Trade-off between Efficiency and Consistency] Under common law, efficiency and consistency are unrelated: common law is consistent regardless of its efficiency. When the civil law becomes more efficient, it also becomes more consistent. Equilibrium welfare under civil law is at its minimum when the variance of legal decisions is maximal ( $\gamma=$ $1 / 2)$ and full efficiency is reached only when the law is consistent $(\gamma \in\{0,1\})$.

\section{Legal Adaptability}

In the previous section, we have supposed that the optimal law is constant. The only source of uncertainty in the economy concerned the type of court making decisions. In this section, we introduce an additional source of uncertainty by supposing that there are shocks that change the optimal law. It is often argued that common law better deals with an uncertain environment and allows for a perfect mix between change and continuity. This section evaluates this claim.

We focus on shocks to the externality parameter $z \cdot{ }^{29}$ We consider that in each $t$, the parameter $z$ can either be $z_{H}$ or $z_{L}$ with $z_{H}>z_{L}$. We suppose that the shock at time $t$ is observed by private parties and by courts at the beginning of the period. Shocks are distributed according to a discrete Markov chain with transition probability: $\pi_{j i}=\operatorname{prob}\left(z_{i} \mid\right.$ $z_{j}$ ) and $\sum_{i=1}^{2} \pi_{j i}=1$, with $j, i=H, L$.

Knowing the transition probability, we can compute the stationary probabilities of $z_{H}$ and $z_{L}$, denoted by $\pi_{H}$ and $\pi_{L}:{ }^{30}$

$$
\pi_{H}=\frac{\pi_{L H}}{\pi_{L H}+\pi_{H L}} \quad \pi_{L}=\frac{\pi_{H L}}{\pi_{L H}+\pi_{H L}}
$$

To simplify the algebra, we henceforth make the assumption that the transition-probability matrix is symmetric, implying that $\pi_{H}=\pi_{L}=1 / 2$. We continue to assume that $\theta=1 / 2$.

\footnotetext{
${ }^{29}$ When shocks concern $\theta$, results are qualitatively similar.

${ }^{30}$ See, for instance, Howard (1960).
} 
Following the incomplete contract literature, we suppose that the code or the precedent cannot be contingent on these shocks. We justify this assumption by assuming that these shocks are difficult to describe in advance, even if their consequences and probabilities are known by all players. ${ }^{31}$

\subsection{Adaptability under Civil Law}

The legislator under civil law writes the code under a double veil of ignorance: without knowing which judge will enforce the law in each period and without knowing which shock will occur in each period. Since the code is written before the $t=0$ shock is realized, the legislator uses the stationary probabilities $\pi_{H}$ and $\pi_{L}$ to compute the expected payoffs. Also, notice that Lemma 1 is still valid to describe the outcome when a benevolent judge decides. In fact, a shock to $z$ changes the slope of the court's reaction function, but it does not change the intersection with the investment rule in Figure 3. Solving for the optimal code, one obtains

$$
l_{s}=\pi_{L}\left(z_{L} \gamma+(1-\gamma)\left(z_{L}+\varepsilon\right)\right)+\pi_{H}\left(z_{H} \gamma+(1-\gamma)\left(z_{H}+\varepsilon\right)\right)
$$

Conservative judges choose $p=l_{s}$, while benevolent judges select $p=l_{s}-\varepsilon$. While the code internalizes the occurrence of the shocks to $z$, in the civil law benevolent as well as conservative judges are totally unresponsive to shocks. The variability of the law does not arise because judges respond to changing economic conditions, but, as in Section 4, it arises because of judicial heterogeneity.

\subsection{Adaptability under Common Law}

Common law is potentially more adaptable to shocks, as benevolent courts observe the shock and can choose any law in the interval $[0, \bar{p}]$. However, common law courts must be cautious. Since the precedent cannot be made contingent on the shock, changing the precedent after a

\footnotetext{
${ }^{31}$ The notion of "undescribable events" has been advanced by Al-Najjar et al. (2007). Note that we are not claiming that in the real world all shocks are undescribable. We focus on undescribable shocks because if courts were facing describable shocks, the analysis here would be identical to the one in the previous sections, after we define the decision space as $[0, \bar{p}] \times\left\{z_{H}, z_{L}\right\}$. Similarly, we do not consider shocks that were not foreseen at $t=0$. Under such shocks the welfare comparison between the two regimes would not be very interesting, as the common law, by making decision sequentially, would likely dominate.
} 
shock is costly because, if tomorrow's shock is different and if a conservative judge enforces the law, the previous precedent will be confirmed, even if it was intended for a different shock.

As we show below, the lower the shock's persistence, the weaker and more cautious the court's response. ${ }^{32}$ In the limit, we find that when shocks are iid, the decision of a benevolent court is identical in both states of the world.

In what follows, we distinguish between iid and persistent shocks.

7.2.1. Independent shocks. When shocks are idd, the probabilities of the two states are $\pi_{H}$ and $\pi_{L}$.

As before, the problem of conservative courts is trivial: they do not innovate at all and defer to past precedents.

We obtain that in both states of the world, the first order condition of a benevolent judge is identical and equal to

$$
e-2 p=\pi_{H} \frac{\delta \gamma}{1-\delta \gamma}\left(p-z_{H}\right)+\pi_{L} \frac{\delta \gamma}{1-\delta \gamma}\left(p-z_{L}\right)
$$

The left-hand side of (25) is the current marginal benefit of lowering $p$ ex-post. The right-hand side is the expected marginal cost of lowering $p$. The reason why the first-order condition is the same regardless of the current shock is twofold. On the one hand, notice that $z$ enters linearly into the current ex post utility. As such, it does not affect the current marginal benefit of decreasing $p$. Second, when shocks are not persistent, the future looks identical in both states. Therefore, the current shock does not affect the right-hand side of (25). We can solve for the equilibrium law under common law and obtain

$$
p_{c}=\delta \gamma\left[\pi_{L} z_{L}+\left(1-\pi_{L}\right) z_{H}\right]
$$

In contrast to Section 5, when $\delta \gamma$ goes to one, the law under the common law regime is not optimal anymore. Instead, common law judges implement the law that is optimal on average, not the one that is currently optimal.

It is often argued that the rule of precedent makes common law adaptable to changing economic conditions (e.g., Beck et al., 2003a, 2005). This section shows that this result

\footnotetext{
${ }^{32}$ Referring to the role of the judge, Cardozo famously wrote: "Justice is not to be taken by storm. She is to be wooed by slow advances." Cardozo (1924, p. 133).
} 
does not hold when economics shocks are iid and when judges can only write "incomplete" precedents.

7.2.2. Persistent shocks. When shocks are persistent, the current shock is a payoffrelevant state because the current state helps us to infer the next-period's shock. Therefore, there are two first-order conditions, one for each state of nature.

Let $p_{c}^{i}$ denote the equilibrium law when the shock is $z_{i}$, with $i=H, L$. The first-order condition when $z_{L}$ occurs is

$$
\begin{aligned}
& {\left[e-2 p_{c}^{L}\right]-\frac{\delta \gamma \pi_{L H}\left(1-\gamma \delta \pi_{L L}\right)+\delta^{2} \gamma^{2} \pi_{L L} \pi_{L H}}{\left(1-\gamma \delta \pi_{L L}\right)\left(1-\gamma \delta \pi_{H H}\right)-\delta^{2} \gamma^{2} \pi_{H L} \pi_{L H}}\left(p_{c}^{L}-z_{H}\right)} \\
& -\frac{\delta^{2} \gamma^{2} \pi_{L H} \pi_{H L}+\delta \gamma \pi_{L L}\left(1-\gamma \delta \pi_{H H}\right)}{\left(1-\gamma \delta \pi_{L L}\right)\left(1-\gamma \delta \pi_{H H}\right)-\delta^{2} \gamma^{2} \pi_{L H} \pi_{H H}}\left(p_{c}^{L}-z_{L}\right)=0
\end{aligned}
$$

The first-order condition when $z_{H}$ occurs is symmetric.

When $\gamma \delta$ is sufficiently close to one and we progressively increase persistence (that is, $\pi_{L L}$ and $\pi_{H H}$ approach one), the decisions of benevolent common law courts are close to the optimum: $p_{c}^{H}$ and $p_{c}^{L}$ are close to $z_{H}$ and $z_{L}$, respectively. The reason is that courts have fewer motives to be cautious and, consequently, they optimally respond to shocks. When instead the shocks become iid, the above condition coincides with (25): the courts do not respond to shocks. The effect of higher $\gamma$ on $\hat{p}_{L}$ and $\hat{p}_{H}$ is ambiguous. On the one hand, as in the model without shocks to $z$, a larger share of conservative judges provides commitment and pushes the laws towards their optimal values (disciplinary effect). But on other other hand, when economic conditions change, a higher $\gamma$ increases the probability that a "bad" precedent stays in place, making courts more cautious in changing the law (incongruity effect).

In Figures 7 and 8 we set $\delta=0.95, z_{L}=0.1$ and $z_{H}=0.3$, and we compute the enforced levels of property-right protection, $p_{c}^{L}$ and $p_{c}^{H}$, for different persistence parameters. For each $\gamma$, the distance between $p_{c}^{U}$ and $p_{c}^{L}$ measures the extent to which common law courts adapt to changing economic conditions. From Proposition 1, we know that the optimal law is equal to 0.1 in the low state and is equal to 0.3 in the high state. We will see that common law courts partially respond to shocks, but less than optimally.

Figure 7 shows that when shocks are not very persistent $\left(\pi_{L L}=\pi_{H H}=0.6\right)$ the laws in the two states are similar and are increasing in $\gamma$. In Figure 8, shocks are more persistent $\left(\pi_{L L}=\pi_{H H}=0.9\right)$ and the laws are farther apart (hence, closer to the optimal values). 
Notice that the effect of $\gamma$ on $\left(p_{c}^{U}-p_{c}^{L}\right)$ is not monotone: common law courts adapt more to changing economic conditions when $\gamma$ is intermediate. To see this, notice in fact that when $\gamma$ is close to one, there is too much inertia under common law. As a result, courts are extremely cautious and choose similar laws in both states. When $\gamma$ is close to zero common law courts make similar decisions for a different reason. When there are no conservative judges, stare decisis cannot play a disciplinary role. Consequently, benevolent judges behave myopically and the equilibrium law coincides with the static law without commitment, which is equal to zero in both states. ${ }^{33}$

Figure 7

Laws: Low Persistence

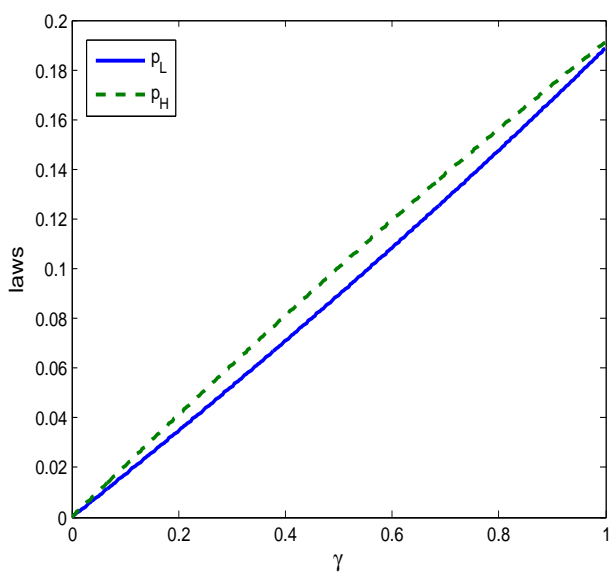

Figure 8

Laws: High Persistence

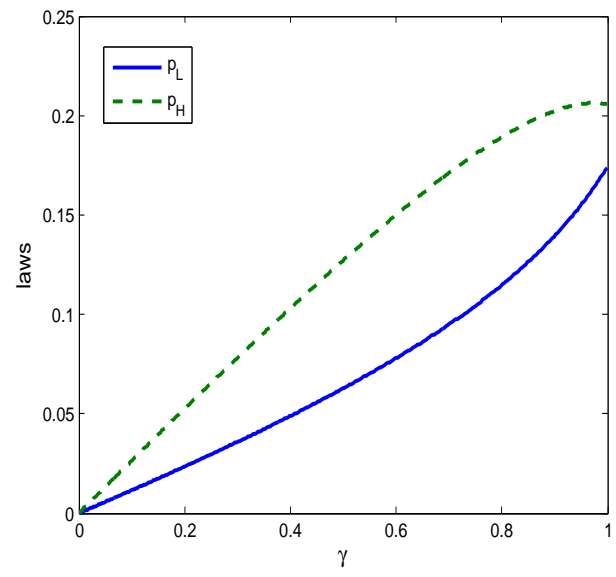

\subsection{Common Law vs Civil Law: a Comparison}

Figures 9 and 10 compare welfare in the two legal systems (see the Appendix for a formal definition of welfare under the two regimes). When shocks are persistent we find that common law might dominate civil law even when $\varepsilon=0$, because it is more adaptable to shocks. When instead shocks are close to being iid, common law is not adaptable (see Section 7.2.1), so that common law dominates civil law only if $\varepsilon$ is sufficiently large.

\footnotetext{
${ }^{33}$ It is interesting to see that $p_{c}^{L}$ (resp. $p_{c}^{H}$ ) is convex (resp. concave) in $\gamma$. The reason is intuitive. Suppose that the shock is $z_{L}$ and consider the effect of higher $\gamma$ on the courts' incentives. As per usual, the "disciplinary effect" is at work, giving courts the incentive to choose higher values of $p$. At the same time, there is no "incongruity effect", as high values of $p$ would also fit well if $z_{H}$ occurs. This is why $p_{c}^{L}$ increases steeply when $\gamma$ increases. Instead, when the shock is $z_{H}$, high values of $p$ will not be appropriate when $z_{L}$ occurs. This is why the disciplinary effect of $\gamma$ on $p_{c}^{H}$ is weakened by the incongruity effect. The overall effect could turn out to be negative when $\gamma$ is close to one.
} 
Expected welfare under common law is not necessarily monotone in $\gamma$ (see Figure 10). As discussed before, this is because when there are many conservative judges, "bad" precedents might stay in place for long periods. This effect counterbalances the positive disciplinary effect of a higher $\gamma$ and might induce judges to respond less to shocks (see Figure 8). Our numerical computations suggest that when shocks are persistent, welfare under common law is not increasing in conservatism: a value of $\gamma$ less than one is actually preferable. However, when shock persistence is low, the higher the number of conservative courts, the higher the welfare under common law.

Finally, notice that persistence of shocks affects welfare under common law, but not under civil law: in fact, the degree of shock persistence does not affect the code and consequently does not enter into welfare under civil law.

Result 3: [Efficiency and Legal Change] When shocks are persistent, common law is more likely to dominate civil law.

The intuition for this result is that when shocks are persistent, the common law is much more adaptable than civil law. This makes it more likely that common law dominates civil law in efficiency terms.

Figure 9

Welfare: Low Persistence

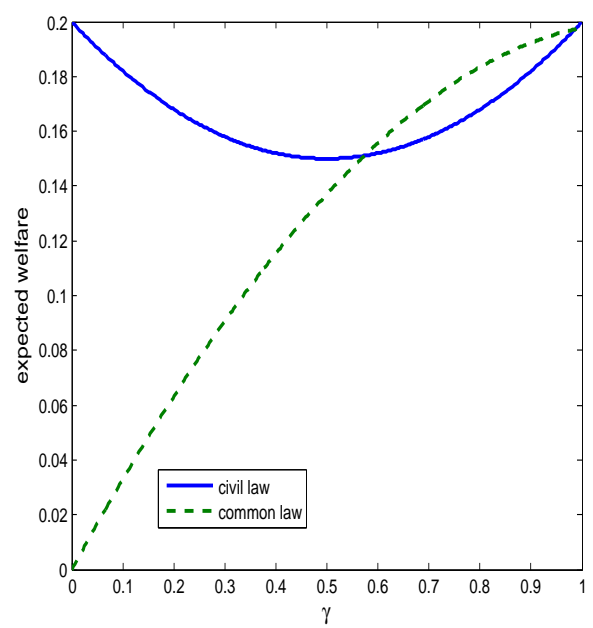

Figure 10

Welfare: High Persistence

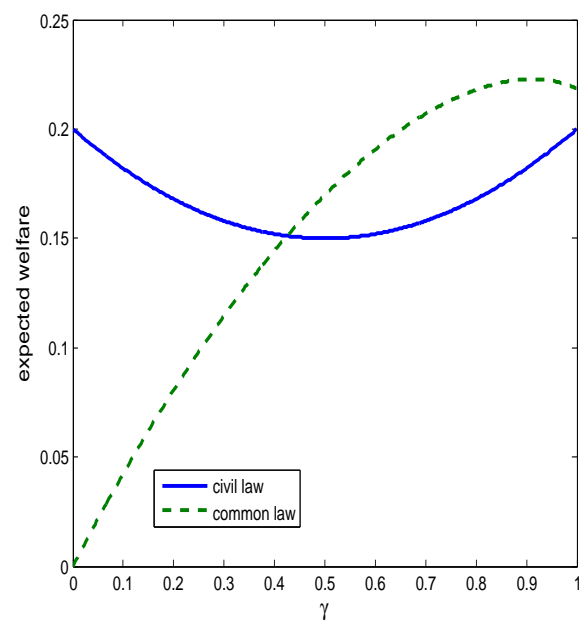

8. Partisan Bias in Courts

The analysis so far has focused on the courts' temptation to reduce property right protection ex-post. The literature has mostly studied another type of judicial bias: the partisan bias, 
which refers to the fact that courts' preferences are biased towards one of the parties. Our model can be easily extended to study partisan bias in courts.

To focus on this alternative source of bias, we shut-down the ex-post bias by supposing that investment is no longer endogenous. We fix $e=1, z=0$ and suppose that investment is costless. Absent any incentives to boost investment, the courts' optimal decisions from an ex ante or an ex post perspective are the same. We also suppose that there are no shocks. The parties' payoffs are now:

$$
\begin{gathered}
u_{A}(p, e)=p, \\
u_{B}(p, e)=-p^{2} .
\end{gathered}
$$

As before, a proportion $\gamma$ of judges mechanically follow the precedent or the statute. Suppose now that a proportion $(1-\gamma) / 2$ of courts are fully biased towards party $A$ and a proportion $(1-\gamma) / 2$ of courts are fully biased towards party $B$. Biased courts in favor of $A$ would like to choose $p=\bar{p}$, while judges biased in favor of $B$ would choose $p=0$.

From (28) and (29), it is immediate to find that when $\theta=1 / 2$ the utilitarian optimum is $p=1 / 2$. Under common law, the rule of precedent reinforces the incentive to make a biased decision: biased courts, by choosing their static optimal law, also increase the probability that this law will be implemented in the future by conservative judges. In the long run common law decisions alternate between 0 and $\bar{p}$. For instance, the law is 0 under two circumstances. First, when the precedent is zero and the judge enforcing the law is conservative. Second, when the judge is biased in favor of $B$.

Under civil law, a benevolent legislator sets the code at $1 / 2$. To the extent that $\varepsilon<1 / 2$, civil law is less volatile and achieves higher welfare. Remarkably, the superiority of civil law holds even if the legislator writing the code is biased. To see this suppose that the legislator is biased towards $B$ so that the code prescribes law 0 . The enforced law under statute law alternates between 0 and $\varepsilon$. The latter possibility will occur with probability $(1-\gamma) / 2$. Note that this outcome is still preferable to the outcome under common law.

Result 4: [Partisan-bias] If there is judicial partisan bias, civil law always dominates common law 
This suggests that if partisan-bias in court is the first-order concern, civil law is preferable.

\section{Conclusions}

This paper sets up a stylized model to analyze judicial decision making. We assume that courts lack commitment in enforcing the law. We compare courts' decisions under the common and the civil law regimes. Our model is able to generate different economic implications under the two legal systems without assuming differences in preferences between judges and legislatures.

Under civil law, the law defining property right protection is set by the legislature in a strategic way to offset the incentives of the courts to deviate ex post. In many cases, the law is set at a higher level than the ex ante optimum, so that the ex post decision is closer to the optimum. Since legislatures face heterogenous judges and cannot tailor the code to particular judges, civil law courts do not treat people equally. Given the same code, some judges interpret the law literally, while others reoptimize ex post.

Under common law, the rule of precedent plays a disciplinary role. The threat that conservative judges in the future will apply the precedent literally helps to sustain the ex ante optimal policy, despite the degree of discretion that courts enjoy. Moreover, eventually common law courts always implement the same decision, which reduces variability of legal decisions.

Regarding the degree of adaptability of both legal traditions, we show that civil law courts do not respond to shocks. Common law courts are responsive to shocks only when shocks are persistent. Common law courts are more cautious in changing the precedent when facing a shock because they are afraid that in the next period - when a new shock occurs - this new precedent may not be justified. We show that common law is preferable to civil law when shocks are persistent, and when the proportion of conservative judges is neither too low nor too high.

We also show that without shocks or when shocks are not persistent, welfare under common law is increasing in the proportion of judges who mechanically follow the precedents. When instead shocks are persistent, the optimal inertia under common law is less than the maximum one.

Finally, if judges do not have credibility problems but they have a partisan bias, common law is less efficient and less consistent than civil law. 
Overall, this paper shows that there exists no clear answer to the question of which is the most efficient legal system. Among other things, the answer depends on the type of uncertainty, on the composition of the judiciary, and on the extent of judicial independence. This is probably the reason why legal systems continuously evolve over time. The U.S. legal system is no exception. As pointed out by Calabresi (1982), "The last fifty to eighty years have seen a fundamental change in American law. In this time we have gone from a legal system dominated by the common law, divined by courts, to one in which statutes, enacted by legislatures, have become the primary source of law." More recently, Ferejohn (2002) sees a shift in lawmaking power away from legislatures and a rise of the centrality of courts. Since any adjustment to the judicial-legislative balance is up to the society, one should model in a more realistic way the political decision process. As a further step toward realism, the assumption that judges and legislatures maximize an utilitarian objective function should be abandoned. For now, we leave this venture to future research. 


\section{References}

Acemoglu, Daron, (2009), Introduction to Modern Economic Growth. Princeton University Press.

Al-Najjar, Nabil I., Luca Anderlini, and Leonardo Felli (2006). "Undescribable Events" The Review of Economic Studies 73 (4): 849-868

Anderlini, Luca, Leonardo Felli, Giovanni Immordino and Alessandro Riboni (2013) "Legal Institutions, Innovation, And Growth" International Economic Review, 54(3): 937-956.

Anderlini, Luca, Leonardo Felli and Alessandro Riboni (2014) "Why Stare Decisis?" Review of Economic Dynamics, 17(4): 726-738.

Ayres, I. (1997) "The Twin Faces of Judicial Corruption: Extortion and Bribery," Denver University Law Review 74: 1231-1253.

Baker, Scott and Claudio Mezzetti (2012) "A Theory of Rational Jurisprudence," Journal of Political Economy 120(3): 513-551.

Bailey, Martin J., and Rubin, Paul H. (1994) "A Positive Theory of Legal Change" International Review of Law and Economics 14: 467-477.

Beck, Thorsten, Asli Demirgüç-Kunt and Ross Levine (2003a) "Law and Finance: Why Does Legal Origin Matter?" Journal of Comparative Economics, 31(4): 653-675.

Beck, Thorsten, Asli Demirgüç-Kunt and Ross Levine (2003b) "Law, Endowments and Finance" Journal of Financial Economics. 70: 137-81.

Beck, Thorsten, Asli Demirgüç-Kunt and Ross Levine (2005) "Law and Firms Access to Finance" American Law and Economics Review vol. 7(1): 211-252.

Besley Timothy and Maitreesh, Ghatak. (2010) "Property Rights and Economic Development." In Dani Rodrik and Mark Rosenzweig, editors: Handbook of Development Economics, Vol. 5, The Netherlands: North-Holland, 2010, pp. 4525-4595.

Besley, Timothy. (1995). "Property rights and investment incentives: Theory and evidence from Ghana." Journal of Political Economy, 103(5), 903-937.

Bond, Philip (2008) "Persistent Court Corruption," The Economic Journal, 118: 13331353.

Bond, Philip (2009) Contracting in the Presence of Judicial Agency The B.E. Journal of Theoretical Economics (Advances) 9(1): Article 36. 
Botero, Juan, Simeon Djankov, Rafael La Porta, Florencio Lopez-de-Silanes, and Andrei Shleifer (2004) "The Regulation of Labor" Quarterly Journal of Economics, 119(4): 13391382 .

Calabresi, Guido (1982) A Common Law for the Age of Statutes. Cambridge: Harvard University Press.

Callander Steven and Tom S. Clark (2016) "Precedent and Doctrine in a Complicated World" American Political Science Review, forthcoming

Cardozo, Benjamin Nathan (1924) The Growth of the Law. New Haven: Yale University Press.

Catala, Pierre, and John A. Weir (1964) "Delict and Torts: A Study in Parallel." Tulane Law Review 38(2): 221-278.

Cervellati, Matteo Piergiuseppe Fortunato and Uwe Sunde (2007) "Consensual and Conflictual Democratization, Rule of Law and Development" CEPR Discussion Paper number 6328

Chen Ying and Hülya Eraslan (2016) "Information Acquisition under Persuasive Precedent versus Binding Precedent" mimeo, Johns Hopkins University

Cooley, Thomas McIntyre (1868) A Treatise on the Constitutional Limitations Which Rest upon the Legislative Power of the States. Boston, Little \& Brown.

Daughety, Andrew and Jennifer Reinganum. (1999) "Stampede to Judgement: Persuasive Influence and Herding Behavior by Courts," American Law and Economics Review, 1, 158189.

Daughety, Andrew and Jennifer Reinganum. (2000). "Appealing Judgments," The Rand Journal of Economics 31, 502-525.

Diermeier Daniel, Georgy Egorov, Konstantin Sonin, (2015) "Endogenous Property Rights" University of Northwestern, mimeo.

Djankov, Simeon. Rafael La Porta, Florencio Lopez-de-Silanes, Andrei Shleifer (2003) "Courts". Quarterly Journal of Economics 118: 457-522.

Djankov, Simeon. Rafael La Porta, Florencio Lopez-de-Silanes, Andrei Shleifer (2002) "The Regulation of Entry." Quarterly Journal of Economics 117(1): 1-37.

Ferejohn, John (2002) "Judicializing Politics, Politicizing Law." Law and Contemporary Problems. 65(3): 41-68. 
Fon Vincy and Francesco Parisi (2006) "Judicial Precedents in Civil Law Systems: A Dynamic Analysis" International Review of Law and Economics 26(4): 519-535.

Howard Ronald A. (1960) Dynamic programming and Markov processes, MIT Press.

Gennaioli, Nicola and Giacomo Ponzetto (2015) "Contract Innovation and Legal Evolution under Imperfect Enforcement" CREI, mimeo.

Gennaioli, Nicola, and Andrei Shleifer (2007a): "Overruling and the Instability of Law, Journal of Comparative Economics, 35, 309-328.

Gennaioli, Nicola, and Andrei Schleifer (2007b) "The Evolution of Common Law." Journal of Political Economy 115(1): 43-68.

Glaeser, Edward L., and Andrei Shleifer (2002) "Legal Origins." Quarterly Journal of Economics 117(4): 1193-1230.

Goodman, J. C. (1978) "An Economic Theory of the Evolution of the Common Law," Journal of Legal Studies 7: 393-406.

Hadfield, G. K. (1992) "Bias in the Evolution of Legal Rules," Georgetown Law Journal, 80: 583-616.

Lamoreaux, Naomi R., and Jean-Laurent Rosenthal (2005) "Legal Regime and Business Organizational Choice: A Comparison of France and the United States during the MidNineteenth Century." American Law and Economics Review, 7 (1): 28-61.

La Porta, Rafael, Florencio López-de-Silanes, Cristian Pop-Eleches, and Andrei Shleifer (2004) "Judicial Checks and Balances" Journal of Political Economy 112(2): 445-470.

La Porta, Rafael, Florencio Lopez-de-Silanes, Andrei Shleifer, and Robert Vishny (1999) "The Quality of Government." Journal of Law, Economics, and Organization 15: 222-79.

La Porta, Rafael, Florencio Lopez-de-Silanes, Andrei Shleifer, and Robert W. Vishny (1998) "Law and Finance", Journal of Political Economy 106: 1113-1155.

La Porta, Rafael, Florencio Lopez-de-Silanes, Andrei Shleifer and Robert W. Vishny (1997) "Legal Determinants of External Finance", Journal of Finance 52: 1131-1150.

La Porta, Rafael, Florencio Lopez-de-Silanes, and Andrei Shleifer (2008) "The Economic Consequences of Legal Origins." Journal of Economic Literature, 46(2): 285-332.

Legros, P., and A. F. Newman (2002) "Courts, Contracts, and Interference," European Economic Review, 46: 734-744. 
Levine, Ross (2005) "Law, Endowments and Property Rights." Journal of Economic Perspectives. 19(3): 61-88.

Levy, Gilat (2005): "Carrierist Judges and the Appeals Process," Rand Journal of Economics, 36, 275-297

Ljungqvist Lars and Thomas Sargent (2012) Recursive Macroeconomic Theory The MIT Press (third edition).

Maskin, Eric, and Jean Tirole (2001) "Markov Perfect Equilibrium. I. Observable Actions." Journal of Economic Theory 100: 191-219.

Maskin, Eric, and Jean Tirole (1999) "Two Remarks on the Property-Rights Literature." Review of Economic Studies 66: 139-149.

Niblett, Anthony, Richard A. Posner, and Andrei Shleifer (2010) "The Evolution of a Legal Rule" The Journal of Legal Studies, 39(2): pp. 325-358.

North Douglass and Barry Weingast (1989) "Constitutions and Commitment: The Evolution of Institutions Governing Public Choice in Seventeenth Century England." Journal of Economic History 49 (1989), 803-32.

Nunn Nathan (2009) "The Importance of History for Economic Development," Annual Review of Economics 1(1): 65-92.

Peters, Christopher J (1996) "Foolish Consistency: On Equality, Integrity, and Justice in Stare Decisis." Yale Law Journal 105(8): 2031-2115.

Ponzetto, G. A. M., and P. A. Fernandez (2008) "Case Law vs. Statute Law: An Evolutionarty Comparison," Journal od Legal Studies 37: 379-430.

Posner, Richard, (2003) The Economic Analysis of Law 6th ed. (1st ed. 1973), Little Brown, Boston.

Priest, G. (1977) "The Common Law Process and the Selection of Efficient Rules," Journal of Legal Studies, 6: 65-82.

Rajan, Raghuram, and Luigi Zingales (2003) "The Great Reversals: The Politics of Financial Development in the 20th Century." Journal of Financial Economics 69(1): 5-50.

Radin, Max (1933) "Case Law and Stare Decisis: Concerning Präjudizienrecht in Amerika." Columbia Law Review 199: 199-212.

Rubin, Paul (1977) "Why is the Common Law Efficient?" Journal of Legal Studies 6: 51-63. 
Rubin, Paul (2000) "Judge-Made-Law" in Bouckaert, Boudewijn and De Geest, Gerrit (eds.), Encyclopedia of Law and Economics, Volume V. The Economics of Crime and Litigation. Cheltenham, Edward Elgar.

Scalia, Antonin G. (1989) "Originalism: The Lesser Evil" University of Cincinnati Law Review 57: 849-865.

Shavell, Steven. (1995) "The Appeals Process as a Means of Error Correction," Journal of Legal Studies, 24, 379-426

Spamann Holger (2010) "The Antidirector Rights Index Revisited" Review of Financial Studies 23: 467-86.

Spitzer, Matt, and Eric Talley (2000): "Judicial Auditing," Journal of Legal Studies, 29, 649-683.

Stokey, Nancy L. (1989) "Reputation and Time Consistency," American Economic Review 79(2): 134-39.

Summers, Robert S. (1982) Instrumentalism and American Legal Theory, Cornell University Press, Ithaca.

Von Mehren, Arthur, T. (1957) The Civil Law System. Englewood Cliffs: Prentice Hall. 


\section{APPENDIX}

Proof of Proposition 2: Consider a one-shot game. Following Ljungqvist and Sargent (2012, p. 940), and using (6), we define by $C$ the set of rational expectations equilibria: $C=\{(e, p) \mid e=p\}$. An equilibrium without commitment $\left(e^{n}, p^{n}\right)$ satisfies the following two conditions: (1) $\left(e^{n}, p^{n}\right) \in C$; (2) Given $e^{n}$, courts have no incentive to deviate: namely, the court chooses $p^{n}$ to maximize (9).

It is easy to verify that regardless of $\theta$ an equilibrium without commitment is given by $(0,0)$. In fact, the two conditions discussed above are satisfied. First, $(0,0) \in C$. Second, when $e^{n}=0$ the court optimally chooses $p^{n}=0$ and has no incentive to deviate. When $\theta \leq 2 / 3,(\bar{p}, \bar{p})$ is also an equilibrium without commitment. This can be seen by observing that $(\bar{p}, \bar{p}) \in C$ and

$$
\bar{p}=\arg \max \theta\left(p \bar{p}-0.5 \bar{p}^{2}\right)+(1-\theta)\left(-p^{2}+\theta z\right)
$$

Proof of Lemma 1: Let any $l_{s} \in[0, \bar{p}]$ be given. We show that when a benevolent court decides, the equilibrium without commitment is $(0,0)$ or $\left(l_{s}-\varepsilon, l_{s}-\varepsilon\right)$.

We need to show that the ex-post rule intersects the investment rule at $l_{s}-\varepsilon$ if $l_{s}-\varepsilon \geq 0$ and at 0 if $l_{s}<\varepsilon$.

When $\theta \leq 2 / 3$, the ex post payoff is concave in $p$ and is maximized by setting $p=\frac{e \theta}{2(1-\theta)}$. Then, given a code $l_{s} \in[0, \bar{p}]$ and given $e$, it is immediate that if $l_{s}+\varepsilon<\frac{e \theta}{2(1-\theta)}$ the court chooses $l_{s}+\varepsilon$. If instead $l_{s}-\varepsilon>\frac{e \theta}{2(1-\theta)}$ the court chooses $l_{s}-\varepsilon$. Finally, if

$$
l_{s}-\varepsilon<\frac{e \theta}{2(1-\theta)}<l_{s}+\varepsilon
$$

the court chooses $\frac{e \theta}{2(1-\theta)}$

We write down the ex-post court's rule for two cases (the other cases can be derived in a similar way). If $0<l_{s}-\varepsilon<l_{s}+\varepsilon<\bar{p}$ and $2\left(l_{s}+\varepsilon\right)(1-\theta) / \theta \leq \bar{p}$ we can write the reaction function of the court:

$$
p^{e x}=\left\{\begin{array}{c}
l_{s}-\varepsilon \text { if } e<\frac{2\left(l_{s}-\varepsilon\right)(1-\theta)}{\theta} \\
\frac{e \theta}{2(1-\theta)} \text { if } \frac{2\left(l_{s}-\varepsilon\right)(1-\theta)}{\theta}<e<\frac{2\left(l_{s}+\varepsilon\right)(1-\theta)}{\theta} \\
l_{s}+\varepsilon \text { if } e<\frac{2\left(l_{s}+\varepsilon\right)(1-\theta)}{\theta}
\end{array}\right.
$$

It is immediate to see that the reaction function intersects the investment rule at $l_{s}-\varepsilon$. Another example is when $0 \leq l_{s}<\varepsilon$ and $2\left(l_{s}+\varepsilon\right)(1-\theta) / \theta \leq \bar{p}$. In this case, we have

$$
p^{e x}= \begin{cases}\frac{e \theta}{2(1-\theta)} \text { if } e<\frac{2\left(l_{s}+\varepsilon\right)(1-\theta)}{\theta} \\ l_{s}+\varepsilon \text { if } e>\frac{2\left(l_{s}+\varepsilon\right)(1-\theta)}{\theta}\end{cases}
$$


The above ex-post rule intersects the investment rule at 0.

In general, it is easy to verify that in all possible cases the ex-post rule intersects the 45 degree line at either 0 (when $0 \leq l_{s}<\varepsilon$ ) or $l_{s}-\varepsilon$ (when $0<l_{s}-\varepsilon$ ).

Proof of Proposition 3: First, we show that the court does not find it optimal to choose $l_{s}>\varepsilon$. This happens when the optimal law is sufficiently large:

$$
z \frac{1-\theta}{2-3 \theta}>\varepsilon
$$

This condition holds for $\theta \in[0,2 / 3]$ when $\varepsilon<z / 2$, as required.

Given that $l_{s}>\varepsilon$, we can write the legislator's problem as

$$
\max _{l_{s} \in[0, \bar{p}]} \gamma\left[\theta \frac{l_{s}^{2}}{2}+(1-\theta)\left(-l_{s}^{2}+l_{s} z\right)\right]+(1-\gamma)\left[\theta \frac{\left(l_{s}-\varepsilon\right)^{2}}{2}+(1-\theta)\left(-\left(l_{s}-\varepsilon\right)^{2}+\left(l_{s}-\varepsilon\right) z\right)\right]
$$

The optimal law is

$$
l_{s}=\frac{1}{2-3 \theta}\{z \gamma(1-\theta)+(1-\gamma)[(z+2 \varepsilon)(1-\theta)-\theta \varepsilon]\}
$$

Using Proposition 1, and assuming that Assumption 1 holds, the optimal code can be written as

$$
l_{s}=p^{\star}+(1-\gamma) \varepsilon
$$

Proof of Proposition 5: We write down welfare under common law. Assuming that at time zero all judges are benevolent (so that the steady state is reached at once), one obtains

$$
\mathcal{V}=\theta \frac{p_{c}^{2}}{2}+(1-\theta)\left(-p_{c}^{2}+p z\right)
$$

where $p_{c}$ is given by Proposition 4 . In the special case $\theta=1 / 2$

$$
\mathcal{V}=-\frac{p_{c}^{2}}{4}+\frac{p_{c} z}{2}
$$

and $p_{c}=z \gamma \delta$.

Welfare under civil law is:

$$
\mathcal{Z}=\gamma\left[\theta \frac{l_{s}^{2}}{2}+(1-\theta)\left(-l_{s}^{2}+l_{s} z\right)\right]+(1-\gamma)\left[\theta \frac{\left(l_{s}-\varepsilon\right)^{2}}{2}+(1-\theta)\left(-\left(l_{s}-\varepsilon\right)^{2}+\left(l_{s}-\varepsilon\right) z\right)\right]
$$


In the special case $\theta=1 / 2$, from Proposition 3 , we set $l_{s}=z+(1-\gamma) \varepsilon$. Then, (40) can be written as

$$
\mathcal{Z}=\gamma(\theta x+(1-\theta)(-2 x+z))+(1-\gamma)(\theta(x-\varepsilon)+(1-\theta)(-2(x-\varepsilon)+z))
$$

We compare (41) and (39). After some algebra, we obtain that (41) is strictly above (39) when $\varepsilon<$ $2 z \sqrt{1-\delta}$. If $\varepsilon>2 z \sqrt{1-\delta}$ there are two intersections: $\gamma_{L}$ and $\gamma_{H}$ which are given by

$$
\begin{aligned}
& \gamma_{L}=\frac{1}{\varepsilon^{2}+z^{2} \delta^{2}}\left(\frac{1}{2} \varepsilon^{2}+z^{2} \delta-\frac{\varepsilon}{2} \sqrt{\varepsilon^{2}-4 z^{2}(1-\delta)}\right) \\
& \gamma_{H}=\frac{1}{\varepsilon^{2}+z^{2} \delta^{2}}\left(\frac{1}{2} \varepsilon^{2}+z^{2} \delta+\frac{\varepsilon}{2} \sqrt{\varepsilon^{2}-4 z^{2}(1-\delta)}\right)
\end{aligned}
$$

Common law dominates the civil law when $\gamma \in\left(\gamma_{L}, \gamma_{H}\right)$, where $0<\gamma_{L}<\gamma_{H}<1$.

\section{Legal Adaptability: Bellman Equation and Value Functions}

Investment rules are now a function of the current state as well. When shock $z_{i}$ occurs, with $i=1,2$, the Bellman equation becomes:

$$
V\left(p, e, z_{i}\right)=\max \left\{W\left(p, e, z_{i}\right)+\delta \sum_{j=L, H} \pi_{i j}\left[(1-\gamma) V\left(p, \Phi\left(p, z_{j}\right), z_{j}\right)+\gamma V^{C}\left(p, \Phi^{C}\left(p, z_{j}\right), z_{j}\right)\right]\right\}
$$

We denote $V^{C}\left(p, \Phi^{C}\left(p, z_{i}\right), z_{i}\right)$ and $W\left(p, \Phi^{C}\left(p, z_{i}\right), z_{i}\right)$ by, respectively, $V^{C}\left(z_{i}\right)$ and $W\left(z_{i}\right)$. After some algebra, for any $i=1,2$ and $j \neq i$, we obtain

$$
\begin{aligned}
V^{C}\left(z_{i}\right)= & \frac{\left[W\left(z_{i}\right)+\delta \pi_{i j}(1-\gamma) V\left(z_{j}\right)+\delta \pi_{i i}(1-\gamma) V\left(z_{i}\right)\right]\left(1-\delta \gamma \pi_{j j}\right)}{\left(1-\gamma \delta \pi_{j j}\right)\left(1-\gamma \delta \pi_{i i}\right)-\gamma^{2} \delta^{2} \pi_{i j} \pi_{j i}}+ \\
& \frac{\delta \gamma \pi_{i j}\left[W\left(z_{j}\right)+\delta \pi_{j j}(1-\gamma) V\left(z_{j}\right)+\delta \pi_{j i}(1-\gamma) V\left(z_{i}\right)\right]}{\left(1-\gamma \delta \pi_{j j}\right)\left(1-\gamma \delta \pi_{i i}\right)-\gamma^{2} \delta^{2} \pi_{i j} \pi_{j i}}
\end{aligned}
$$

These expressions allow to write down the first-order conditions of benevolent courts that we derived in Section 7.

\section{Legal Adaptability: Welfare definitions under Common Law and Civil Law}

Recalling that $\pi_{H}=\pi_{L}=1 / 2$, welfare under the veil of ignorance (before time 0 shock) under civil law is

$\mathcal{Z}=\frac{1}{2}\left[\gamma W\left(l_{s}, l_{s} ; z_{L}\right)+(1-\gamma) W\left(l_{s}-\varepsilon, l_{s}-\varepsilon ; z_{L}\right)+\gamma W\left(l_{s}, l_{s} ; z_{H}\right)+(1-\gamma) W\left(l_{s}-\varepsilon, l_{s}-\varepsilon ; z_{H}\right)\right]$ 
where $l_{s}$ is derived in (24).

Under common law, we keep assuming that at $t=0$, when there is no precedent, all judges are benevolent. Expected welfare is defined as follows:

$$
\begin{aligned}
\mathcal{V}= & \frac{1}{2}\left[W\left(p_{c}^{L}, p_{c}^{L}, z_{L}\right)+\delta \sum_{j=H, L} \pi_{L j}\left[(1-\gamma) V\left(p_{c}^{J}, z_{j}\right)+\gamma V^{C}\left(p_{c}^{L}, z_{j}\right)\right]+\right. \\
& +\frac{1}{2}\left[W\left(p_{c}^{H}, p_{c}^{H}, z_{H}\right)+\delta \sum_{j=H, L} \pi_{H j}\left[(1-\gamma) V\left(p_{c}^{J}, z_{j}\right)+\gamma V^{C}\left(p_{c}^{H}, z_{j}\right)\right]\right]
\end{aligned}
$$

